\title{
Soil Respiration in the Profiles of Forest Soils in Inland Dunes
}

\section{Zofia Fischer', Lidiya Dubis ${ }^{1,2^{*}}$ (])}

${ }^{1}$ The Faculty of Mathematics, Informatics and Landscape, Department of Landscape Ecology, The John Paul II Catholic University of Lublin, Lublin, Poland

${ }^{2}$ Ivan Franko National University of Lviv, Faculty of Geography, Lviv, Ukraine

Email: *lida.dubis@gmail.com

How to cite this paper: Fischer, A. and Dubis, L. (2019) Soil Respiration in the Profiles of Forest Soils in Inland Dunes. Open Journal of Soil Science, 9, 75-90. https://doi.org/10.4236/ojss.2019.95005

Received: June 3, 2019

Accepted: May 27, 2019

Published: May 30, 2019

Copyright (C) 2019 by author(s) and Scientific Research Publishing Inc. This work is licensed under the Creative Commons Attribution International License (CC BY 4.0).

http://creativecommons.org/licenses/by/4.0/

\begin{abstract}
Forest soil profiles of two dunes within the European belt of inland dunes were analysed in the laboratory. We carried out respirometric measurements of carbon dioxide production and oxygen consumption for every horizon of the studied soils while simultaneously quantifying the organic matter and humidity. Oxygen consumption and carbon dioxide excretion decreased exponentially with depth. The oxygen consumption decrease was less rapid than the decrease in carbon dioxide production. We found a statistical significant linear dependence between oxygen consumption and carbon dioxide excretion, and organic matter content and soil water capacity. Respiration processes in the profiles were divided into two strata; oxygen respiration dominated in the first and fermentation processes in the second. We estimated total respiration in the studied profiles for an area of $1 \mathrm{~m}^{2}$ down to around $1 \mathrm{~m}$ depth. We concluded that when assessing the soil's role in carbon cycling in an ecosystem, it is necessary to consider both the respiratory and fermentation strata, as both produce large quantities of carbon dioxide. The main factor determining carbon dioxide production intensity is organic matter content; thus the distribution of organic matter in the soil profile determines carbon cycling intensity.
\end{abstract}

\section{Keywords \\ $\mathrm{CO}_{2}$, RQ, Soil Horizons, Organic Matter}

\section{Introduction}

Soil carbon dioxide excretion has recently become an important area of research, as the soil is responsible for $60 \%-80 \%$ of $\mathrm{CO}_{2}$ emissions in forest ecosystems [1] [2]. There have been many studies on metabolic processes in soil, but they pri- 
marily concern the surface horizon or measurements of $\mathrm{CO}_{2}$ excretion from the surface. The review of Kuzyakow [3] discussed the diversity of methods applied in this field, which results from, amongst others, the range of factors driving $\mathrm{CO}_{2} \mathrm{ex}-$ cretion from the soil. Moreover, the paper warned against making generalisations and suggested caution in drawing conclusions from published results. Field investigations of soil respiration in the soil profile are usually based on probe measurements of changes in amounts of carbon dioxide [4] [5]. On the other hand, laboratory investigations are sparse due to methodical limitations (difficulties relating to the maintenance of anaerobic conditions) and primarily concern the reactions of soil to changes in environmental factors [6].

There have been many laboratory investigations of soil (soil samples) and field investigations of the soil surface in different ecosystems, and these have shown that a large portion of the organic carbon in soil is found in the surface horizon [1] [7]. However, to understand overall carbon cycling in an ecosystem it is necessary to understand the dynamics of carbon in the deeper soil horizons [6] [8]. In reality, these deeper soil horizons excrete low amounts of carbon dioxide, but they are often deep [9] and their features depend on the type of soil in question. The excretion of $\mathrm{CO}_{2}$ from the soil surface can tell us much, but it must be remembered that excretion is the product of two processes, carbon dioxide production in the soil and diffusion [10] [11]. Diffusion depends on the physical characteristics of soil [12]. Metabolic processes are, of course, also widely dependent on the physical and chemical characteristics of soil. However, Fierer and co-authors [6] showed that basic environmental factors like temperature, moisture, and organic substance content affect the metabolism of the soil surface differently than that of the deeper horizons. This difference is caused by differences in the microorganism populations between the horizons. Deeper soil horizons diverge from the surface in a variety of ways, but mainly in their oxygenation and organic matter content. In the present study, it was assumed that to understand respiration processes in the deeper soil horizons it is necessary to understand their reactions to basic environmental factors under anaerobic conditions, especially humidity and organic matter content [6] [13]. It was also assumed that the thermal conditions in the deeper horizons are relatively stable and that their impact on respiration is generally understood [14]. Humidity and organic matter content in both the surface and deeper horizons depend on their location within an ecosystem and the relief of the terrain. Location within the relief also to a large extent defines the soil profile structure. The research of Wiaux [15] showed that carbon dioxide excretion from a soil profile at the peak of a loess hill significantly differs from that at the foot of the hill. This was evidently due to differences in the thermal-humidity conditions, in both the surface and deeper horizons. The investigations of Wiaux [15] primarily concerned $\mathrm{CO}_{2}$ excretion from the soil surface, but measurements carried out at different depths showed how the physical characteristics of every soil horizon can impact the intensity of $\mathrm{CO}_{2}$ excretion.

The main objective of the present study was to investigate under laboratory 
conditions respiration in soil sampled from various horizons of two soil profiles. We analysed the oxygen consumption, $\mathrm{CO}_{2}$ excretion and respiratory quotient $\mathrm{RQ}$. The investigations were carried out in anaerobic conditions while maintaining the appropriate humidity level (GWC, WHC) and soil organic matter content (SOM).

To minimise differences in physical characteristics between given soil horizons, two soil profiles from the peaks of inland dunes in the European dune belt were chosen for analysis. These soils were composed of aoelian sands with similar particle size compositions and were from locations with similar relief. These were forest soils-Podzol soils. In the European dune belt, aeolian sands have similar mineral compositions (68\% - 98\% quartz) [16] [17] [18].

\section{Materials and Methods}

\subsection{The Study Site}

The studied soil profiles were sampled from the European dune belt (European sand belt) [17] [19] [20] [21] et al. Basic profile 1 was from Ukraine (Male Polissia region), and basic profile 2 was from the ancient Vistula River valley in Poland. Additionally, to complement the analysis, we included profile 3, which was also obtained from Male Polissia in Ukraine (2017 May). The climate of the study area is temperate. Some years it varies from Atlantic type to more continental. Average air temperature in 2017 was equal $10.3^{\circ} \mathrm{C}$, and average yearly precipitation amounts to $745.2 \mathrm{~mm}$.

Site 1. The dune is located in Ukraine (geographic coordinates: $50^{\circ} 15^{\prime} 20.97^{\prime \prime} \mathrm{N}$, $24^{\circ} 19^{\prime} 36.06^{\prime E} \mathrm{E}$. This is a parabolic type dune with a distinct shape. Profile 1 lies on the dune's peak. The top is covered in a coniferous forest dominated by pine-Pinus sylvestris $\mathrm{L}$. with an admixture of oak-Quercus robur L. and hornbeam-Carpinus betulus $\mathrm{L}$.

Site 2. A parabolic dune in Poland within Kampinos Forest (geographic coordinates: $52^{\circ} 20^{\prime} 21.20^{\prime \prime} \mathrm{N}, 20^{\circ} 51^{\prime} 26.00^{\prime \prime} \mathrm{E}$ ) on the northern outskirts of Warsaw. The dune is in a forest dominated by Pinus sylvestris L. with an admixture of Quercus robur $\mathrm{L}$.

Site 3. The dune is located in Ukraine (geographic coordinates: $50^{\circ} 15^{\prime} 12.75^{\prime \prime} \mathrm{N}$, $24^{\circ} 19^{\prime} 46.10^{\prime E}$ ). Profile 3 (the additional profile) lies on the peak of a parabolic dune covered in coniferous forest dominated by Pinus sylvestris L. with an admixture of Quercus robur $\mathrm{L}$ with Carpinus betulus $\mathrm{L}$. The parabolic dunes (Sites 1 and 3) are situated parallel to each other and are connected by arms.

\subsection{Soil Sampling}

Soil samples were taken from every genetic horizon of the studied profiles (Table 1). Each soil sample weighed about $1 \mathrm{~kg}$. Every sample was placed in a waterproof container to maintain natural humidity levels.

\subsection{Laboratory Analyses}

1) Respiration ( $\mathrm{OCD}-$ oxygen consumption, $\mathrm{PCO}_{2}$ - production of $\mathrm{CO}_{2}$, $\mathrm{RQ}-$ 
Table 1. Characteristics of the soil profile horizons.

\begin{tabular}{|c|c|c|c|c|}
\hline \multicolumn{2}{|c|}{ Genetic horizon } & \multirow{2}{*}{$\begin{array}{l}\text { GWC } \\
\text { m; se }\end{array}$} & \multirow{2}{*}{$\begin{array}{l}\text { WHC } \\
\text { m; se }\end{array}$} & \multirow{2}{*}{$\begin{array}{l}\text { SOM } \\
\text { m; se }\end{array}$} \\
\hline Symbols & $\begin{array}{l}\text { Horizon depth, } \\
\text { from - to, cm }\end{array}$ & & & \\
\hline \multicolumn{5}{|c|}{ Profile 1} \\
\hline $\mathrm{O} / \mathrm{A}$ & $0-2$ & $0.1 ; 0.001$ & $0.406 ; 0.002$ & $0.054 ; 0.001$ \\
\hline A & $2-12$ & $0.080 ; 0.001$ & $0.359 ; 0.003$ & $0.022 ; 0.000$ \\
\hline Es & $12-25$ & $0.046 ; 0.002$ & $0.271 ; 0.003$ & $0.016 ; 0.000$ \\
\hline Bs & $25-76$ & $0.042 ; 0.000$ & $0.258 ; 0.004$ & $0.013 ; 0.000$ \\
\hline $\mathrm{B} / \mathrm{C}$ & $76-140$ & $0.027 ; 0.003$ & $0.188 ; 0.008$ & $0.004 ; 0.000$ \\
\hline $\mathrm{C}$ & $140-160$ & $0.037 ; 0.002$ & $0.195 ; 0.003$ & $0.004 ; 0.000$ \\
\hline \multicolumn{5}{|c|}{ Profile 2} \\
\hline $\mathrm{O} / \mathrm{A}$ & $0-6$ & $0.181 ; 0.003$ & $1.043 ; 0.016$ & $0.253 ; 0.005$ \\
\hline A & $6-13$ & $0.090 ; 0.001$ & $0.396 ; 0.007$ & $0.116 ; 0.005$ \\
\hline Es & $13-21$ & $0.033 ; 0.001$ & $0.229 ; 0.010$ & $0.025 ; 0.000$ \\
\hline Bs & $21-70$ & $0.031 ; 0.002$ & $0.263 ; 0,004$ & $0.008 ; 0.000$ \\
\hline $\mathrm{B} / \mathrm{C}$ & $70-110$ & $0.030 ; 0.001$ & $0.233 ; 0.002$ & $0.002 ; 0.000$ \\
\hline $\mathrm{C}$ & $110-120$ & $0.038 ; 0.006$ & $0.234 ; 0.009$ & $0.002 ; 0.000$ \\
\hline \multicolumn{5}{|c|}{ Profile 3} \\
\hline $\mathrm{O} / \mathrm{A}$ & $0-5$ & $0.356 ; 0.006$ & $0.678 ; 0.012$ & $0.128 ; 0.003$ \\
\hline A & $5-17$ & $0.059 ; 0.000$ & $0.27 ; 0.004$ & $0.016 ; 0.000$ \\
\hline Es & $17-23$ & $0.057 ; 0.004$ & $0.244 ; 0.009$ & $0.012 ; 0.000$ \\
\hline Bs & $23-60$ & $0.048 ; 0.001$ & $0.278 ; 0.003$ & $0.010 ; 0.000$ \\
\hline $\mathrm{B} / \mathrm{C}$ & $60-115$ & $0.040 ; 0.001$ & $0.201 ; 0.003$ & $0.003 ; 0.000$ \\
\hline $\mathrm{C}$ & $115-130$ & $0.051 ; 0.002$ & $0.207 ; 0.004$ & $0.002 ; 0.000$ \\
\hline
\end{tabular}

Genetic horizon: O/A-transitional horizon from $\mathrm{O}$ (organic horizon) to A; A-ochrik; Es-albic; Bs-spodic; B/C-transitional horizon to horizon C; C-bedrock horizon.

respiratory quotient). We used the volumetric method with a Scholander type respirometer to determine both oxygen consumption and carbon dioxide production. Each experimental series consisted of two parts. In the first, without hydroxide in the flasks, changes in volumes were recorded for 5 hours; this gave the sum of $\mathrm{CO}_{2}$ changes and $\mathrm{O}_{2}$ consumption. In the second, after placing filter paper soaked with $\mathrm{NaOH}$ solution into the respirometric chamber, we recorded the oxygen consumption (OCD) for another 5 hours, taking readings every 30 minutes. The bath temperature was $17.0^{\circ} \mathrm{C}$. The humidity was always controlled. For profile 2, the measurements were done twice, once at the soil sampling humidity and then again with the humidity increased up to $80 \%$ of the maximal water holding capacity (WHC). For profile 1, there was only one measurement, at a humidity of $80 \%$ of maximal WHC. Containers were filled to the top with soil and then rammed with a wooden rammer. They were then covered and placed into a water bath with a regulated temperature for 48 hours. After this time had elapsed, the measurements were started. The container was a cylinder 
of $4 \mathrm{~cm}$ in diameter and $4 \mathrm{~cm}$ in height. Next, we plotted the results against the time of the readings; the slope coefficient of the regression $(\beta 1)$ was the rate $\left(\mathrm{O}_{2}\right.$ consumption-OCD or $\mathrm{PCO}_{2}$ ). The respective regression coefficients were all $\mathrm{r}>$ 0.95. They were later corrected for pressure and temperature, multiplied by the calibration factor and related per gram of dry soil per hour. The method was described in details by Fischer and Blažka [22]. Measurements were repeated 12 times for each soil sample.

2) Humidity (GWC-gravimetric water content, WHC-water holding capacity, $\mathrm{dm}$-dry mass). Our procedure was essentially based on Grace et al. [23], Priha and Smolander [24] with minor modifications. GWC and other contents are given as ratios, not in $\%$. Dry mass was determined by drying at $110^{\circ} \mathrm{C}$ to constant weight.

3) Soil Organic Matter (SOM). SOM was estimated as the loss of weight in ignition to constant weight (LOI) at $500^{\circ} \mathrm{C}$ on selected samples.

4) Granulomentric composition. Particle-size analysis was done with the laser particle measuring device Analysette 22 Comfort. Particle-size measurements were done with a step of 0.5 phi.

\subsection{Statistics}

Means (m), standard deviations (s), coefficients of variation (cv) and standard errors of the mean (se) were determined for all data series. A T-test for equality of means was used to determine the statistical significance of mean differences. A test for regression co-linearity determination was also carried out.

\section{Results}

SOM, GWC, WHC and granulometric composition were determined for six horizons in each of profiles 1, 2 and 3. The characteristics of these profiles are presented in Table 1. Respiromentric investigations PCO2, OCD, RQ were carried out for all horizons of profiles 1 and 2.

\subsection{Soil Profile Characteristics}

The investigated profiles were classified as Podzol soil. Six horizons were demarcated in each of the profiles (O/A-A-Es-Bs-B/C-C). In the horizons of the investigated soil profiles, fine or medium grain, poorly or medium sorted sands dominated (Table 2). In the profiles, the granulomentric fractions were divided into three main groups-sand, powder and silt. The percentage contents of these groups were analysed in each horizon except in the O/A-A horizon, in view of its high organic matter content. The type of relation was similar for all three soil profiles. As expected, the amount of sand increased with depth. Meanwhile, the proportion of powder and silt decreased. However, it is worth noting that in the investigated soils an increase in the proportion of the finest particles was not observed in horizon Bs. It can be assumed that this is due to the location of the profiles on the peaks of dunes, where are the best interior drainage conditions. 
Table 2. Granulometric features of the studied soil profile horizons obtained by the method of Folk and Ward (1957).

\begin{tabular}{|c|c|c|c|c|c|}
\hline \multicolumn{2}{|c|}{ Genetic horizon } & \multicolumn{3}{|c|}{ Granulometric parameters } & \multirow[b]{2}{*}{ Granulometric features description } \\
\hline Symbols & $\begin{array}{l}\text { Horizon } \\
\text { depth, } \\
\text { from - to, } \\
\text { cm }\end{array}$ & $\begin{array}{l}\text { Average } \\
\text { grain } \\
\text { diameter } \\
\mathrm{Mz}, \varphi\end{array}$ & $\begin{array}{l}\text { Sorting, } \\
\sigma_{1}\end{array}$ & $\begin{array}{l}\text { Skewness } \\
\left(\mathrm{SK}_{1}\right)\end{array}$ & \\
\hline \multicolumn{6}{|c|}{ Profile 1} \\
\hline $\mathrm{O} / \mathrm{A}$ & $0-2$ & $* * * * *$ & $* * * * *$ & $* * * * *$ & $* * * * *$ \\
\hline A & $2-12$ & 2.171 & 1.427 & 0.457 & $\begin{array}{l}\text { Fine-grain sand; poorly sorted; } \\
\text { very positive slant distribution }\end{array}$ \\
\hline Es & $12-25$ & 2.145 & 1.428 & 0.458 & $\begin{array}{l}\text { Fine-grain sand; poorly sorted; } \\
\text { very positive slant distribution }\end{array}$ \\
\hline Bs & $25-76$ & 2.01 & 1.488 & 0.416 & $\begin{array}{l}\text { Fine-grain sand; poorly sorted; } \\
\text { very positive slant distribution }\end{array}$ \\
\hline $\mathrm{B} / \mathrm{C}$ & $76-140$ & 1.993 & 0.992 & 0.291 & $\begin{array}{l}\text { Medium-grain sand; moderately sorted; } \\
\text { very positive slant distribution }\end{array}$ \\
\hline $\mathrm{C}$ & $140-160$ & 1.967 & 0.866 & 0.272 & $\begin{array}{l}\text { Medium-grain sand; moderately sorted; } \\
\text { positive slant distribution }\end{array}$ \\
\hline \multicolumn{6}{|c|}{ Profile 2} \\
\hline $\mathrm{O} / \mathrm{A}$ & $0-6$ & $* * * * *$ & $* * * * *$ & $* * * * *$ & $* * * * *$ \\
\hline $\mathrm{A}$ & $6-13$ & 3.347 & 1.999 & 0.509 & $\begin{array}{l}\text { Very fine-grain sand; poorly sorted; } \\
\text { very positive slant distribution }\end{array}$ \\
\hline Es & $13-21$ & 2.944 & 1.725 & 0.545 & $\begin{array}{l}\text { Fine-grain sand; poorly sorted; } \\
\text { very positive slant distribution }\end{array}$ \\
\hline Bs & $21-70$ & 2.315 & 1.297 & 0.357 & $\begin{array}{l}\text { Fine-grain sand; poorly sorted; } \\
\text { very positive slant distribution }\end{array}$ \\
\hline $\mathrm{B} / \mathrm{C}$ & $70-110$ & 2.113 & 0.604 & 0.028 & $\begin{array}{l}\text { Fine-grain sand; moderately well sorted; } \\
\text { symetric distribution }\end{array}$ \\
\hline $\mathrm{C}$ & $110-120$ & 1.859 & 0.621 & 0.007 & $\begin{array}{l}\text { Medium-grain sand; moderately well } \\
\text { sorted; symetric distribution }\end{array}$ \\
\hline \multicolumn{6}{|c|}{ Profile 3} \\
\hline $\mathrm{O} / \mathrm{A}$ & $0-5$ & $* * * * *$ & $* * * * *$ & $* * * * *$ & $* * * * *$ \\
\hline $\mathrm{A}$ & $5-17$ & 2.753 & 1.921 & 0.593 & $\begin{array}{l}\text { Fine-grain sand; poorly sorted; } \\
\text { very positive slant distribution }\end{array}$ \\
\hline Es & $17-23$ & 1.966 & 1.345 & 0.385 & $\begin{array}{l}\text { Medium-grain sand; poorly sorted; } \\
\text { very positive slant distribution }\end{array}$ \\
\hline Bs & $23-60$ & 1.945 & 1.432 & 0.392 & $\begin{array}{l}\text { Medium-grain sand; poorly sorted; } \\
\text { very positive slant distribution }\end{array}$ \\
\hline $\mathrm{B} / \mathrm{C}$ & $60-115$ & 1.944 & 0.788 & 0.083 & $\begin{array}{l}\text { Medium-grain sand; moderately sorted; } \\
\text { symetric distribution }\end{array}$ \\
\hline $\mathrm{C}$ & $115-130$ & 1.668 & 0.738 & 0.103 & $\begin{array}{l}\text { Medium-grain sand; moderately sorted; } \\
\text { very positive slant distribution }\end{array}$ \\
\hline
\end{tabular}


The highest organic matter contents (SOM) (Table 1) and humidities (GWC, WHC) were in horizons O/A-A of the investigated profiles. These dunes are characterized by significant variations in relief, as well as differentiation in organic matter accumulation, both spatially and in the soil profile. The highest amounts of organic matter accumulate where the dunes occur in deflation valleys and in the troughs between the dunes (often wetland areas). The lowest SOM is found on dune peaks.

\subsection{Humidity, Soil Organic Matter Content and Respiration in the Soil Profile}

Both the oxygen consumption and carbon dioxide production decreased exponentially with profile depth (Figure 1). The difference in respiration between the surface horizons of the profiles was caused by the different humidities during soil sampling. Nevertheless, the overall character of the curves of the profiles was similar. The main reason for this was that the main factors determining respiration, namely organic matter content and soil humidity, also decreased exponentially with depth (Figure 2). The rate of decrease was highest for organic matter content $\left(\mathrm{SOM}=0.193 \times \mathrm{h}^{-0.886}\right.$. The relationship between respiration, and organic matter content and humidity is described by a statistically significant linear regression $\mathrm{OCD}=18,492 \times \mathrm{SOM}-0.097, \mathrm{R}^{2}=0.945, \mathrm{~N}=180 ; \mathrm{PCO}_{2}=9087 \times$ $\mathrm{SOM}-0.008, \mathrm{R}^{2}=0.925 ; \mathrm{N}=180 . \mathrm{OCD}=5948 \times \mathrm{WHC}-1310, \mathrm{R}^{2}=0.985, \mathrm{~N}=$ $180 ; \mathrm{PCO}_{2}=2907 \times \mathrm{WHC}-0.599, \mathrm{R}^{2}=0.954 ; \mathrm{N}=180$.

Separating the effects of humidity and SOM is difficult because these factors are closely correlated with each other $\left(\mathrm{R}^{2}>0.9\right)$. In all three profiles, consecutive horizons from $\mathrm{O} / \mathrm{A}$ to Bs had statistically different average organic matter contents and water holding capacities. Only between $\mathrm{B} / \mathrm{C}$ and $\mathrm{C}$ where there are no differences between the average parameters $(\mathrm{p}>0.05)$.

Bearing in mind the determinative role of water holding capacity in the retention

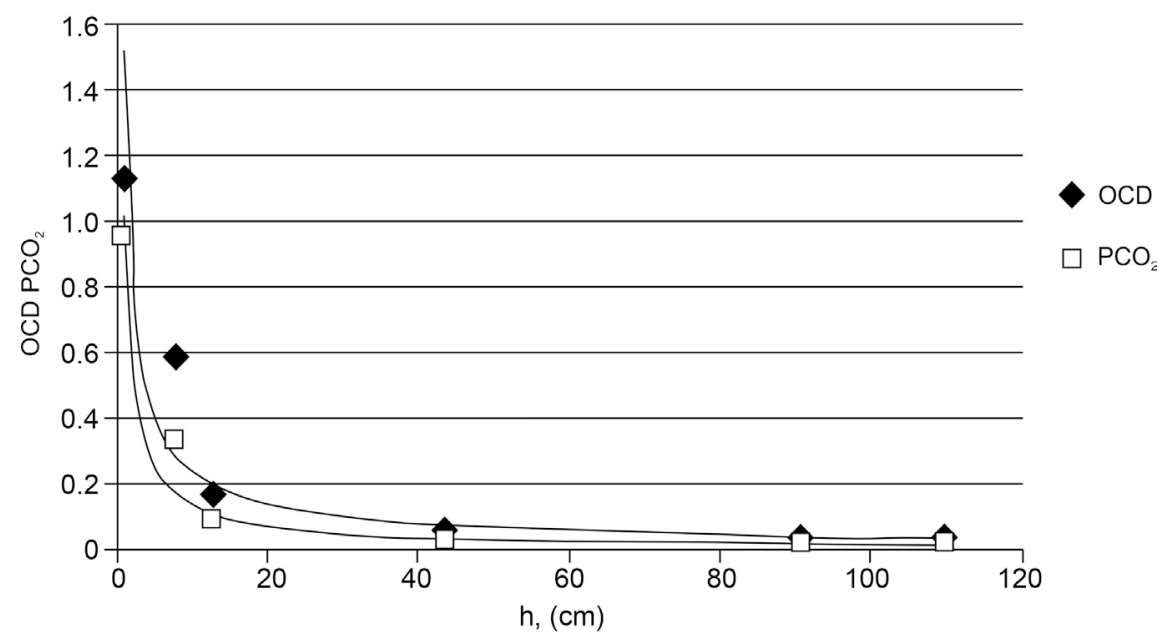

Figure 1. Dependencies of oxygen consumption (OCD) and carbon dioxide production $\left(\mathrm{PCO}_{2}\right)$ on depth $(\mathrm{h})$. Profile 2. $\mathrm{OCD}=1.518(\mathrm{~h})^{-0.81}, \mathrm{R}^{2}=0.928, \mathrm{~N}=72 ; \mathrm{PCO}_{2}=$ $1.2(\mathrm{~h})^{-0.962}, \mathrm{R}^{2}=0.951, \mathrm{~N}=72$. 


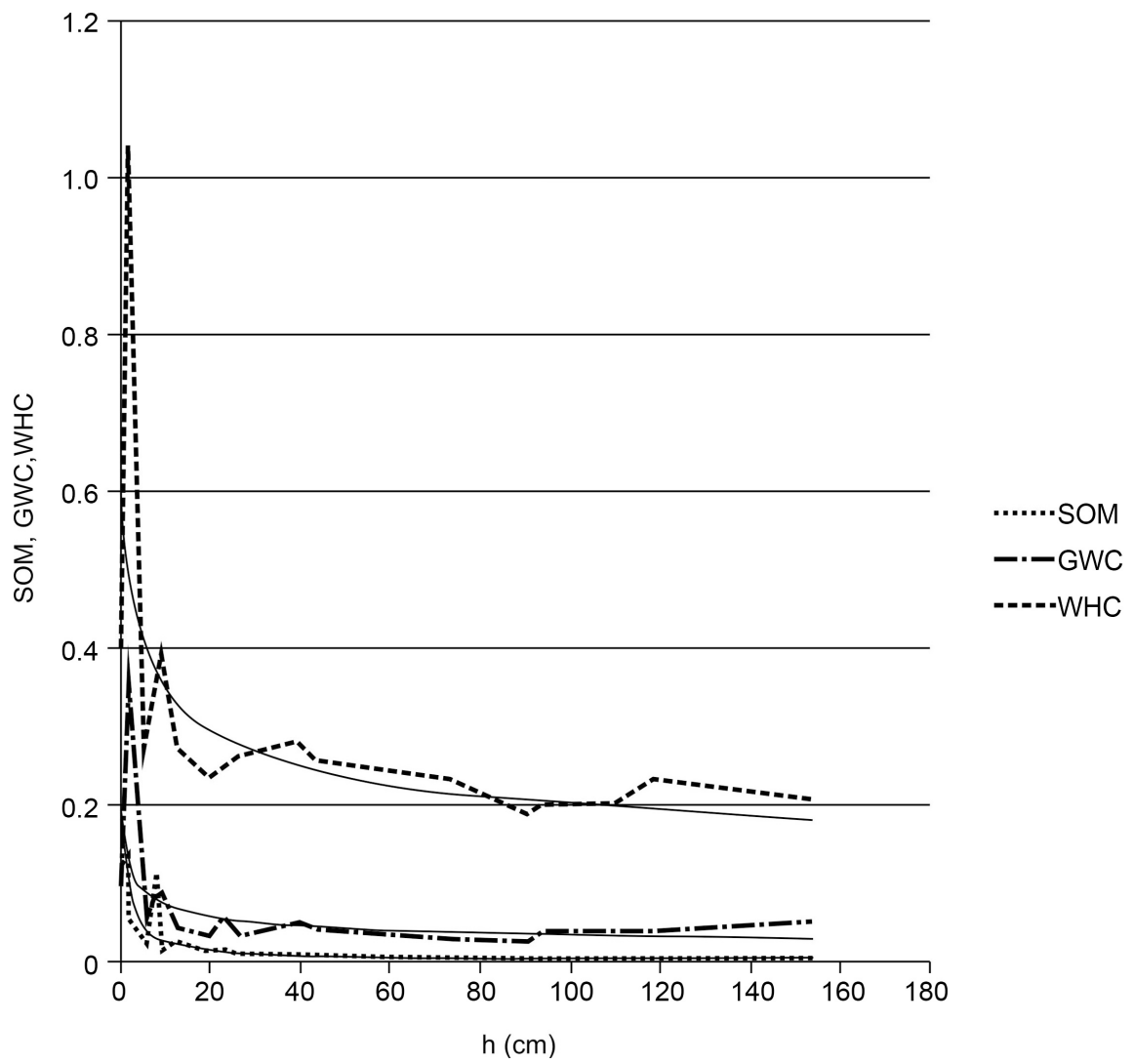

Figure 2. Dependencies of soil organic matter content (SOM), gravimetric water content (GWC), water holding capacity (WHC) on soil horizon depth $(\mathrm{h}, \mathrm{cm}$ ) of profiles 1, 2 and 3. $\mathrm{SOM}=0.193(\mathrm{~h})^{-0.886} ; \mathrm{R}^{2}=0.879, \mathrm{~N}=180$; GWC $=0.156(\mathrm{~h})^{-0.342} ; \mathrm{R}^{2}=0.704, \mathrm{~N}=180$; $\mathrm{WHC}=0.594(\mathrm{~h})^{-0.237}, \mathrm{R}^{2}=0.754, \mathrm{~N}=180$.

of water in the soil, especially in the subsurface horizons, we asked the following question: does WHC depend more on humidity (GWC), which decreases with profile depth, or does it mostly depend on the organic matter. WHC relates to organic matter according to the linear regression $\mathrm{WHC}=3.153 \times \mathrm{SOM}+0.2121$, $\mathrm{R}^{2}=0.92$. In the years 2012-2013, in the same areas and in various seasons, an investigation of the relation between SOM and WHC was carried out on 240 soil samples; this relation was also found to be quite significant $R^{2}=0.88$, with the equation $\mathrm{WHC}=5.58 \times \mathrm{SOM}+0.50[25]$.

An analysis of regression co-linearity was carried out to clarify this problem. The results showed there was a closer relationship between WHC and SOM than between WHC and GWC (Table 3). This relation indicates the close link between organic matter and water holding capacity, which has been found before in numerous studies [25] [26] and others. An analysis of regression co-linearity was also carried out to analyse the correlation between the granulometric percentage shares (sand, powder, silt) and SOM, WHC and GWC in the analysed profiles. There were no significant correlations in all variants of the model.

The humidity (GWC) during soil sampling was different for each soil horizon, varying between $12 \%$ - $22 \%$ of maximal water holding the capacity for each 
Table 3. Coefficients of co-linear regression. Dependent variable WHC; predictors GWC and SOM. $\mathrm{R}^{2}=0.928, \mathrm{n}=170$.

\begin{tabular}{ccccc}
\hline \multicolumn{4}{c}{ Coefficients $^{\mathbf{a}}$} \\
\hline Model & $\begin{array}{c}\text { Unstandardised } \\
\text { Coefficiens } \\
\text { B }\end{array}$ & $\begin{array}{c}\text { Standardised } \\
\text { coefficients } \\
\text { Beta }\end{array}$ & t-test & significance \\
\hline intercept & 0.189 & & 31.153 & 0.000 \\
GWC & 0.478 & 0.180 & 6.221 & 0.000 \\
SOM & 2.713 & 0.829 & 28.632 & 0.000 \\
\hline
\end{tabular}

${ }^{\mathrm{a}}$ Response variable: WHC.

given horizon. To obtain data on how respiration changes in response to changes in soil humidity, each horizon was hydrated up to $80 \%$ of its maximal water capacity. $80 \%$ of water capacity is generally considered to be optimal. The obtained results are presented in Figure 3; the calculations were based on percentage values, assuming that respiration at the moment of sampling was $100 \%$. These results show that oxygen consumption during moistening increases more than carbon dioxide production. This could be due to the addition of extra air with the water. However, the deeper horizons $(\mathrm{Bs}, \mathrm{B} / \mathrm{C}, \mathrm{C})$ reacted less to moistening than the other horizons. Using microbiological methods, Fierer and his team concluded that "The relative responses of $\mathrm{C}$ mineralization rates to changes in soil moisture, temperature, and nutrient levels varied with soil depth" [6]. Our results showing the effect of increased humidity on soil respiration demonstrate that the surface and sub-surface horizons responded differently. Moreover, there were further differences between the subsurface horizons. It is likely that the poor organic matter content in horizons Bs, B/C, C had some significance. These results fully confirm the conclusion of Fierer [6], that there exists a different carbon cycling mechanism in the deeper soil horizons than in the surface and subsurface horizons.

The parameter RQ can indirectly tell us about this mechanism. In research on soil metabolism this parameter is very important, but usually does not give definitive answers on what is dominating-respiration or fermentation; it only gives information about tendencies. Angert [11] showed how for soils the parameter RQ is difficult to interpret, as it is dependent on many factors and varies widely. However, by assuming a simplification it is possible to see some tendencies; namely, if the RQ parameter varies between 0.5 and 1.0 then respiration (aerobic) processes dominate, and if it is smaller than 0.5 or larger than 1.0 then fermentation processes dominate. The data on oxygen consumption and carbon dioxide production for each horizon of profile 2 was used to calculate the RQ parameter. The results were divided into 2 groups. The first included results higher than 1.0 and lower than 0.5 , for which fermentation processes were assumed to dominate, and the second results from 0.5 to 1.0 , for which respiration processes were assumed to dominate (Figure 4). In horizon $\mathrm{B} / \mathrm{C}$ respiration was at a lower level that could be detected using our method, so it is not included in 


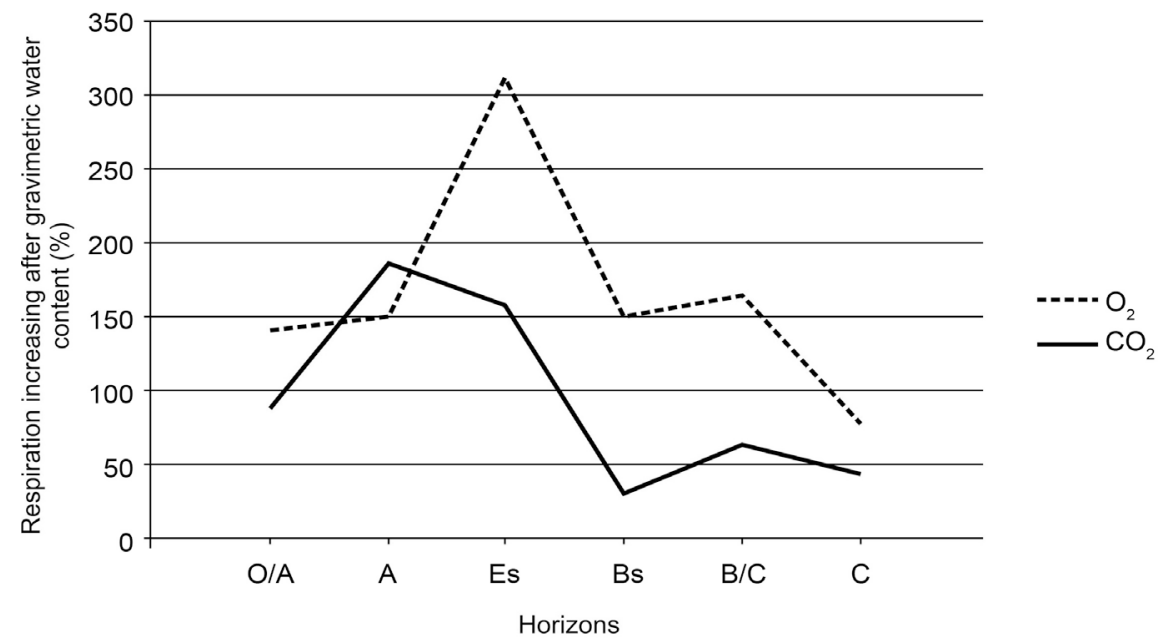

Figure 3. Respiration increase (\%) after gravimetric water content (GWC) was increased from $16 \%$ to $80 \%$ of maximal water holding capacity (WHC).

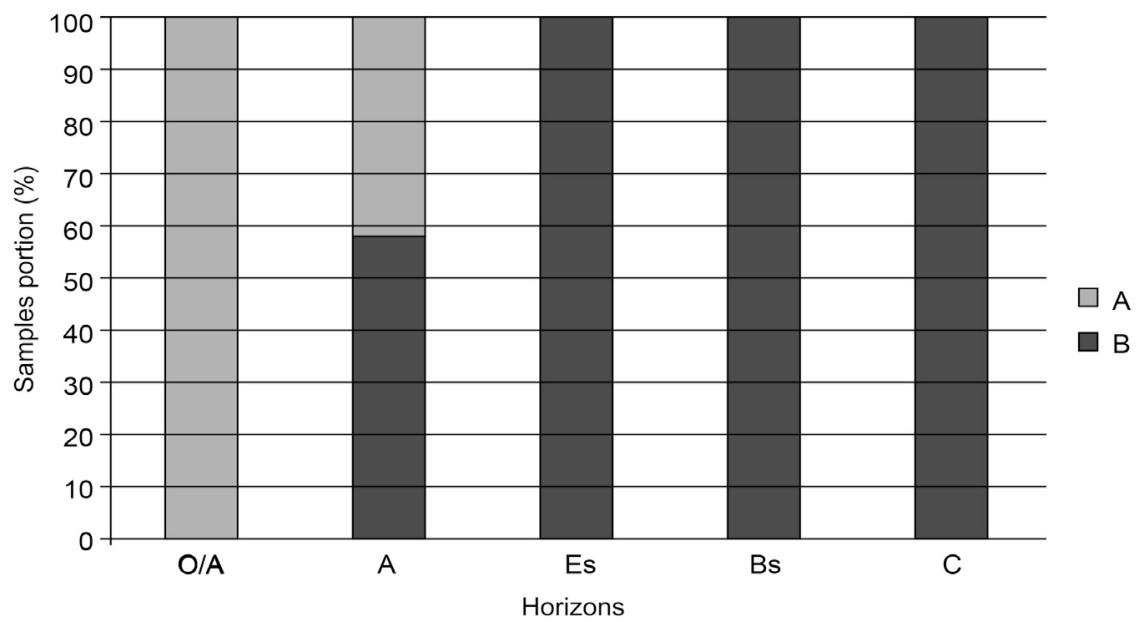

Figure 4. Percentage of samples with RQ within the limits $0.5-1$ (A) and rest $0.5<$ and $1>$ (B) for the horizons of profile 2 at the natural humidity level; $100 \%=61 \mathrm{~N}$.

the presented Figure 4. The results suggest that respiration dominates in the surface horizons and fermentation dominates in the deeper horizons. It is likely that horizon O/A contains the most air; this is why respiration processes dominate in this layer and fermentation does not yet need to be considered. Horizon A is a transitional layer, and from horizon Es-about $13 \mathrm{~cm}$ from the soil surface-there is a noticeable decrease in oxygen levels, with simultaneous declines in organic matter content and humidity (lower water holding capacity) and thus fermentation processes begin to dominate. These results fully confirm the thesis of Fierer and co-authors, who analyzed the soil profile in two separate strata-surface and sub-surface [6] - and asked how significant is fermentation in the deeper horizons for the carbon dynamics of the whole soil profile.

\subsection{Respiration in the Soil Profile}

Although oxygen consumption and carbon dioxide excretion in the soil surface 
are important indicators of the processes ongoing in soil, the whole soil system is important for carbon cycling in an ecosystem. For this reason, we estimated the respiration of the whole of profiles 1 and 2. The calculations were done for an area of $1 \mathrm{~m}^{2}$ and a depth of around $1 \mathrm{~m}$, with the soil profile divided into two strata, one with respiration dominating and another with fermentation processes dominating. The respiration results and profile characteristics are presented in Table 4. Bearing in mind that these results only have an approximate character, we can deduce that the analysed profiles were similar in their granulometric composition, relief and soil organic matter content but different with regards to their metabolic processes. Oxygen consumption and carbon dioxide production in profile 2 were most intensive in the surface stratum (77\% and 72\% Table 4$)$. On the other hand, in profile 1 respiration in the surface stratum (55\% and 51\%) was close to that of the fermentation stratum ( $44 \%$ and $48 \%)$. This resulted in profile 1 producing slightly more carbon dioxide and consuming much more oxygen. This is likely because although the soil organic matter content in both profiles is similar, its distribution within the profiles is different (Table 4). The fermentation stratum of both profiles contains more than $90 \%$ of the whole soil mass; however, the respiration stratum of profile 1 had only about $22 \%$ of the organic matter, whereas that of profile 2 had $60 \%$ (Table 4 ). The differing vertical distributions of the organic matter are perhaps caused by differences in the filtration abilities of the A horizons, which depend on granulometries. The average particle size (Table 2) for horizon A of profile 1 was $2.171 \varphi(222.1 \mu \mathrm{m})$ and for profile $2-3.347 \varphi(98.25 \mu \mathrm{m})$.

Different soil filtration abilities led to differences in organic matter decomposition that caused the amount of carbon dioxide excretion in the respiration stratum of profile 1 to be $55 \%$, whereas in profile $2 \%-77 \%$. Davidson et al. [27] cautiously estimated that in their studied mixed forest in Massachusetts, profile O was the source of $40 \%-48 \%$ of annual carbon dioxide production. On the other hand, investigations of boreal forest in Finland showed that horizon A was responsible for $69.9 \%$ of carbon dioxide production [14]. However, it is clear

Table 4. Characteristics of the profile divided into strata A-respiration dominated and B-fermentation dominated. Humidity (GWC) at approximately $80 \%$ WHC; dry mass.

\begin{tabular}{|c|c|c|c|c|c|c|c|c|c|}
\hline \multirow{2}{*}{ Strata } & \multirow{2}{*}{$\begin{array}{c}\text { Thickness, } \\
\text { cm }\end{array}$} & \multicolumn{2}{|c|}{ Weight } & \multicolumn{2}{|c|}{ SOM } & \multicolumn{2}{|c|}{$\mathrm{PCO}_{2}$} & \multicolumn{2}{|c|}{ OCD } \\
\hline & & $\mathrm{kg}$ & $\%$ & $\mathrm{~kg}$ & $\%$ & $\mathrm{ml} / \mathrm{h}$ & $\%$ & $\mathrm{ml} / \mathrm{h}$ & $\%$ \\
\hline \multicolumn{10}{|c|}{ Profile 1} \\
\hline A & 13 & 196.845 & 7.74 & 5.692 & 22.68 & 75.683 & 55.87 & 139.119 & 51.55 \\
\hline B & 147 & 2347.407 & 92.26 & 19.405 & 77.32 & 59.782 & 44.13 & 130.779 & 48.45 \\
\hline$A+B$ & 160 & 2544.252 & 100.00 & 25.097 & 100.00 & 135.465 & 100.00 & 269.898 & 100.00 \\
\hline \multicolumn{10}{|c|}{ Profile 2} \\
\hline A & 10 & 85.500 & 4.81 & 15.253 & 60.29 & 126.421 & 77.48 & 251.070 & 72.69 \\
\hline $\mathrm{B}$ & 105 & 1692.700 & 95.19 & 10.047 & 39.71 & 36.755 & 22.52 & 94.308 & 27.31 \\
\hline$A+B$ & 115 & 1778.200 & 100.00 & 25.299 & 100.00 & 163.175 & 100.00 & 345.378 & 100.00 \\
\hline
\end{tabular}


that these proportions change depending on the season, ecosystem and climate [4]. In our investigations, which were just a snapshot and did not look at multiple seasons, and which only described production in the studied profiles and not excretion from the soil surface, the carbon dioxide production in the surface strata was quite high. We obtained similar results for oxygen consumption. The transfer of part of the soil organic matter in profile 1 to the fermentation stratum led to this stratum having a much higher oxygen consumption and carbon dioxide excretion. The interrelations between organic matter and $\mathrm{CO}_{2}$ excretion in a soil profile are discussed in, amongst others, Delogu et al. [1]. Finally, our results indicate that the distribution of organic matter in a soil profile significantly affects the intensity of carbon cycling. An amount of organic matter located in the surface respiration stratum leads to a noticeably higher amount of $\mathrm{CO}_{2}$ production and oxygen consumption than an equivalent amount located in deeper strata. However, this does not mean that in investigations of carbon cycling in an ecosystem the fermentation stratum can be left out, as its respirometric processes can comprise up to even half of all processes in a profile. Organic matter decomposition in the profile depends to a large extent on the relief, soil filtration ability and its location.

\section{Discussion}

Carbon cycling in ecosystems not only depends on the soil surface stratum but also on deeper strata, with the distribution of the organic matter in the profile playing a very important role. Its distribution can vary widely and depends on many factors like climatic, geologic, and geomorphologic conditions [28] [29] [30]. Since the rise of agriculture, the role of organic matter in the soil has been of key interest. Of particular importance is that soil organic matter is the source of nutrients for both plants and microorganisms. However, over the last years, the organic matter has also been considered to be a substratum with water holding ability. F. J. Veihmeyer was the first scientist to raise this point, at a meeting of the American Society of Agronomy in 1937 [31]. But over the next years, this problem was somehow forgotten. Recently, as water has become increasingly important [32], water holding capacity has become a hot topic all over the world [33] [34] [26] et al. Hudson [31], in a comprehensive paper, extensively debated the role of soil organic matter in water holding capacity, and discussed how widely the results of researchers varied. He assumed that this variation was due to bad research design, and excessive differences in soil texture and insufficient differences in the amounts of organic matter (between studies). In our investigations, texture differentiation (granulometric composition) of the soil horizons was not significantly related to soil organic matter content or water capacity. Instead, the dependence of WHC on SOM was quite significant $\left(\mathrm{R}^{2}=0.92\right)$ in each tested soil profile. The investigations of Hudson [31] also found that soils with high organic matter content have a much higher water holding ability than soils with a similar texture but lower organic matter content. Hudson suggested that 
the amount of organic matter plays a significant role in this difference. Blažka drew attention to the fact that the higher water holding capacity of soils with high organic matter content may be due to the hydration of the organic substance by the creation of so-called "water bridges" [25]. In this way, soil organic matter has to be considered not only a nutrient but also an element that widely regulates humidity.

In light of the variation in humidity and organic matter distribution, which are dependent on the type of soil and its location in the relief and ecosystem, it is necessary to take into account the depth of both a soil profile's respiration and fermentation strata during carbon cycle modelling.

\section{Conclusions}

Our research on the soil profiles of inland dune peaks led us to conclude the following:

- The main factor determining levels of carbon dioxide production in the soil profile was organic matter content, the location of which in the profile influenced carbon cycling.

- Oxygen consumption and carbon dioxide excretion decreased exponentially with depth. Oxygen consumption decreased with depth less rapidly than carbon dioxide production.

- Consecutive horizons, from O/A to Es, had statistically different organic matter contents and water holding capacities, whereas horizons $\mathrm{B} / \mathrm{C}$ and $\mathrm{C}$ did not have such differences.

- The effect of increasing humidity on oxygen consumption and carbon dioxide excretion was different for every soil horizon, but the effect was less pronounced in the deeper horizons than in the surface strata.

- In terms of its respiration processes, every profile could be divided into two strata, the surface horizon, where aerobic respiration dominates, and the other horizons, where fermentation processes dominate. In assessing the soil's role in carbon cycling in an ecosystem, it is necessary to consider both the respiratory and fermentation strata because both produce carbon dioxide in considerable quantities.

\section{Conflicts of Interest}

The authors declare no conflicts of interest.

\section{References}

[1] Delogu, E., Longdoz, B., Plain, C. and Epron, D. (2016) Seasonal and Vertical Variations in Soil $\mathrm{CO}_{2}$ Production in a Beech Forest: An Isotopic Flux-Gradient Approach. Biogeosciences Discussions. https://doi.org/10.5194/bg-2016-194

[2] Granier, A., Loustau, D. and Bréda, N. (2000) A Generic Model of Forest Canopy Conductance Dependent on Climate, Soil Water Availability and Leaf Area Index. Annals of Forest Science, 57, 755-765. https://doi.org/10.1051/forest:2000158

[3] Kuzyakov, Y. (2006) Sources of $\mathrm{CO}_{2}$ Efflux from Soil and Review of Partitioning 
Methods. Soil Biology and Biochemistry, 38, 425-448.

https://doi.org/10.1016/j.soilbio.2005.08.020

[4] Vargas, R., Baldocchi, D.D., Allen, M.F., Bahn, M., Black, T.A., Collins, S.L., Yuste, J.C., Hirano, T., Jassal, R.S., Pumpanen, J. and Tang, J. (2010) Looking Deeper into the Soil: Biophysical Controls and Seasonal Lags of Soil $\mathrm{CO}_{2}$ Production and Efflux. Ecological Applications, 20, 1569-1582. https://doi.org/10.1890/09-0693.1

[5] Tang, J., Baldocchi, D.D., Qi, Y. and Xu, L. (2003) Assessing Soil $\mathrm{CO}_{2}$ Efflux Using Continuous Measurements of $\mathrm{CO}_{2}$ Profiles in Soils with Small Solid-State Sensors. Agricultural and Forest Meteorology, 118, 207-220. https://doi.org/10.1016/S0168-1923(03)00112-6

[6] Fierer, N., Allen, A.S., Schimel, J.P. and Holden, P.A. (2003) Controls on Microbial $\mathrm{CO}_{2}$ Production: A Comparison of Surface and Subsurface Soil Horizons. Global Change Biology, 9, 1322-1332. https://doi.org/10.1046/j.1365-2486.2003.00663.x

[7] Wiaux, F., Vanc Oost, K. and Vanclooster, M. (2014) Quantitative Estimation and Vertical Partitioning of the Soil Carbon Dioxide Fluxes at the Hillslope Scale on a Loess Soil. Biogeosciences Discussions, 11, 13699-13737.

https://doi.org/10.5194/bgd-11-13699-2014

[8] Ryan, M.G. and Law, B.E. (2005) Interpreting, Measuring, and Modeling Soil Respiration. Biogeochemistry, 73, 3-27. https://doi.org/10.1007/s10533-004-5167-7

[9] Risk, D., Kellman, L. and Beltrami, H. (2002) Carbon Dioxide in Soil Profiles: Production and Temperature Dependence. Geophysical Research Letters, 29, 11-1-11-4. https://doi.org/10.1029/2001GL014002

[10] Pingintha, N., Leclerc, M., Beasley, J., Zhang, G. and Senthong, C. (2010) Assessment of the Soil $\mathrm{CO}_{2}$ Gradient Method for Soil $\mathrm{CO}_{2}$ Efflux Measurements: Comparison of Six Models in the Calculation of the Relative Gas Diffusion Coefficient. Tellus B: Chemical and Physical Meteorology, 62, 47-58. https://doi.org/10.1111/j.1600-0889.2009.00445.x

[11] Angert, A., Yakir, D., Rodeghiero, M., Preisler, Y., Davidson, E.A. and Weiner, T. (2015) Using $\mathrm{O}_{2}$ to Study the Relationships between Soil $\mathrm{CO}_{2}$ Efflux and Soil Respiration. Biogeosciences, 12, 2089-2099. https://doi.org/10.5194/bg-12-2089-2015

[12] Davidson, E.A. and Trumbore, S.E. (1995) Gas Diffusivity and Production of $\mathrm{CO}_{2}$ in Deep Soils of the Eastern Amazon. Tellus B: Chemical and Physical Meteorology, 47, 550-565. https://doi.org/10.3402/tellusb.v47i5.16071

[13] Fischer, Z., Blažka, P. and Dubis, L. (2017) Respiration Rates of Organic Soil Depending on Changes of Moisture and Aeration. Open Journal of Soil Science, 7, 101-110. https://doi.org/10.4236/ojss.2017.76008

[14] Pumpanen, J., Ilvesniemi, H., Kulmala, L., Siivola, E., Laakso, H., Kolari, P., Helenelund, C., Laakso, M., Uusimaa, M. and Hari, P. (2007) Respiration in Boreal Forest Soil as Determined from Carbon Dioxide Concentration Profile. Soil Science Society of America Journal, 72, 1187-1196.

https://doi.org/10.2136/sssaj2007.0199

[15] Wiaux, F., Vanclooster, M. and Van Oost, K. (2015) Vertical Partitioning and Controlling Factors of Gradient-Based Soil Carbon Dioxide Fluxes in Two Contrasted Soil Profiles along a Loamy Hillslope. Biogeosciences, 12, 4637-4649. https://doi.org/10.5194/bg-12-4637-2015

[16] Mycielska-Dowgiałło, E. (1993) Estimates of Late Glacial and Holocene Aeolian Activity in Belgium, Poland and Sweden. Boreas, 22, 165-170.

https://doi.org/10.1111/j.1502-3885.1993.tb00177.x 
[17] Woronko, B. (2012) Zapis procesów eolicznych w osadach piaszczystych plejstocenu na wybranych obszarach Polski środkowej i północno-wschodniej. Wydział Geografii i Studiów Regionalnych Uniwersytet Warszawski, Warszawa.

[18] Dubis, L. (2010) The Lithological Features of Relict Dunes Deposits in Small Polissya. Physical Geography and Geomorphology, 4, 127-136.

[19] Koster, E.A. (1988) Ancient and Modern Cold-Climate Aeolian Sand Deposition: A Review. Journal of Quaternary Science, 3, 69-83. https://doi.org/10.1002/jqs.3390030109

[20] Zeeberg, J.J. (2008) The European Sand Belt in Eastern Europe and Comparison of Late Glacial Dune Orientation with GCM Simulation Results. Boreas, 27, 127-139. https://doi.org/10.1111/j.1502-3885.1998.tb00873.x

[21] Kasse, C. (2002) Sandy Aeolian Deposits and Their Relations to Climate during the Last Glacial Maximum and Lateglacial in Northwest and Central Europe. Progress in Physical Geography, 26, 507-532. https://doi.org/10.1191/0309133302pp350ra

[22] Fischer, Z. and Blažka, P. (2015) Soil Respiration in Drying of an Organic Soil. Open Journal of Soil Science, 5, 181-192. https://doi.org/10.4236/ojss.2015.59018

[23] Grace, C., Hart, M. and Brookes, P.C. (2006) Laboratory Manual of the Soil Microbial Biomass Group, Rothamsted Research.

[24] Priha, O. and Smolander, A. (2003) Short-Term Uptake of ${ }_{15} \mathrm{NH}^{4+}$ into Soil Microbes and Seedlings of Pine, Spruce and Birch in Potted Soils. Biology and Fertility of Soils, 37, 324-327.

[25] Blažka, P. and Fischer, Z. (2014) Moisture, Water Holding, Drying and Wetting in Forest Soils. Open Journal of Soil Science, 4, 174-184. https://doi.org/10.4236/ojss.2014.45021

[26] Minasny, B. and McBratney, A.B. (2018) Limited Effect of Organic Matter on Soil Available Water Capacity. European Journal of Soil Science, 69, 39-47. https://doi.org/10.1111/ejss.12475

[27] Davidson, E.A., Savage, K.E., Trumbore, S.E. and Borken, W. (2006) Vertical Partitioning of $\mathrm{CO}_{2}$ Production within a Temperate Forest Soil. Global Change Biology, 12, 944-956. https://doi.org/10.1111/j.1365-2486.2005.01142.x

[28] Rasmussen, C., Heckman, K., Wieder, W.R., Keiluweit, M., Lawrence, C.R., Berhe, A.A., Blankinship, J.C., Crow, S.E., Druhan, J.L., Pries. C.E.H., Marin-Spiotta, E., Plante, A.F., Schädel, C., Schimel, J.P., Sierra, C.A., Thompson, A. and Wagai, R. (2018) Beyond Clay: Towards an Improved Set of Variables for Predicting Soil Organic Matter Content. Biogeochemistry, 137, 297-306. https://doi.org/10.1007/s10533-018-0424-3

[29] Leinemann, T., Preusser, S., Mikutta, R., Kalbitz, K., Cerli, C., Höschen, C., Mueller, C.W., Kandeler, E. and Guggenberger, G. (2018) Multiple Exchange Processes on Mineral Surfaces Control the Transport of Dissolved Organic Matter through Soil Profiles. Soil Biology and Biochemistry, 118, 79-90. https://doi.org/10.1016/j.soilbio.2017.12.006

[30] Kramer, M.G., Lajtha, K. and Aufdenkampe, A.K. (2017) Depth Trends of Soil Organic Matter C:N and ${ }_{15} \mathrm{~N}$ Natural Abundance Controlled by Association with Minerals. Biogeochemistry, 136, 237-248. https://doi.org/10.1007/s10533-017-0378-x

[31] Hudson, B.D. (1994) Soil Organic Matter and Available Water Capacity. Journal of Soil and Water Conservation, 49, 189-194.

[32] Brevik, E.C., Cerdà, A., Mataix-Solera, J., Pereg, L., Quinton, J.N., Six, J. and Van Oost K. (2015) The Interdisciplinary Nature of Soil. Soil, 1, 117-129. https://doi.org/10.5194/soil-1-117-2015 
[33] Lacambra, L.C.J., Andray, A.B. and Francés, F.S. (2010) Influence of the Soil Water Holding Capacity on the Potential Distribution of Forest Species. A Case Study: The Potential Distribution of Cork Oak (Quercus suber L.) in Central-Western Spain. European Journal of Forest Research, 129, 111-117. https://doi.org/10.1007/s10342-008-0251-5

[34] Lawes, R.A., Oliver, Y.M. and Robertson, M.J. (2009) Integrating the Effects of Climate and Plant Available Soil Water Holding Capacity on Wheat Yield. Field Crops Research, 113, 297-305. https://doi.org/10.1016/j.fcr.2009.06.008 